\title{
Implementasi Metode Model View Controller (MVC) Dalam Rancang Bangun Website SMK Yayasan Bakti Prabumulih
}

\author{
Khana Wijaya ${ }^{1}$, Andi Christian ${ }^{2}$ \\ ${ }^{1}$ STMIK Prabumulih \\ e-mail: khanawijaya90@gmail.com \\ ${ }^{2}$ STMIK Prabumulih \\ e-mail: andichristian cdm@yahoo.com
}

\begin{abstract}
Cara Sitasi: Wijaya, K., \& Christian, A. (2019, Maret). Implementasi Metode Model View Controller (MVC) Dalam Rancang Bangun Website SMK Yayasan Bakti Prabumulih. (S. Dalis, Ed.) Paradigma - Jurnal Komputer dan Informatika, 21(1), 95-102. doi:10.31294/p.v21i1.5092
\end{abstract}

\begin{abstract}
Website or site may be defined as a collection of pages displaying text data, still or motion picture data, animation data, sound, video and or all of them, both static and dynamic, forming a series of interconnected buildings in which each linked to the network pages (hyperlinks). The school website has a very important role in education. SMK Bakti Prabumulih Foundation is one of the private schools that have two majors, automotive motorcycle and computer engineering and networking techniques, but this school does not have a website so many people who do not know yet remember this school is still new. In making this website the author also apply the MVC method as an option in the development of the system. The View Controller (MVC) model is a concept introduced by the inventor of Smalltalk (Trygve Reenskaug) to create one type of network data into another data type along with processing (model), isolating from the process of manipulation (controller) and view to be represented on a user interface. This application is made using the programming language Personal Hypertext Preprocessor (PHP) as a programming language and design editor Macromedia Dreamweaver, and MySQL as its database so it can help penginputan data quickly, precisely and efficiently.
\end{abstract}

Keywords: Website, Model View Controller Method (MVC), PHP, MySQL

\section{PENDAHULUAN}

Pemanfaatan teknologi informasi dan komunikasi dalam dunia pendidikan semakin dirasakan manfaatnya dan telah menjadi suplemen yang penting bagi siswa dan manajemen sekolah (Kadek Wibowo, 2015). Dengan adanya internet masyarakat akan dengan mudah mendapatkan informasi yang ingin mereka cari salah satunya informasi tentang sekolah, caranya dengan membuka halaman Website sekolah yang diinginkan..

Website atau situs dapat diartikan sebagai kumpulan halaman yang menampilkan informasi data teks, data gambar diam atau gerak, data animasi, suara, video dan atau gabungan dari semuanya, baik yang bersifat statis maupun dinamis yang membentuk satu rangkaian bangunan yang saling terkait dimana masing-masing dihubungkan dengan jaringanjaringan halaman (hyperlink) (Anggiani Septima, Eko Retnandi, Asep Deddy, 2012).

Website sekolah memiliki peran yang sangat penting dalam dunia pendidikan (Imam Teguh
Syamnugroho, Rissal Efendi, 2014). Karena suatu sistem imformasi berbasis Website sekolah merupakan salah satu bentuk media publikasi elektronik yang dapat digunakan sebagai salah satu sarana bagi sekolah yang ingin menunjukkan jati diri mereka pada masyarakat luas, sekaligus sebagai media informasi bagi orang-orang luar yang ingin mengetahui lebih lengkap seluk beluk tentang sekolah tersebut (Anggiani Septima, Eko Retnandi, Asep Deddy, 2012). Dengan adanya Website sekolah maka dapat membantu memberikan informasi kepada siswa, guru dan masyarakat tentang sekolah mereka dengan mudah dan cepat, juga bisa membantu meningkatkan kualitas sekolah.

SMK Yayasan Bakti Prabumulih merupakan salah satu sekolah swasta yang memiliki dua jurusan yaitu teknik otomotif sepeda motor dan teknik komputer dan jaringan, namun sekolah ini belum memiliki Website sehingga banyak masyarakat yang belum mengetahuinya mengingat sekolah ini masih baru. Karena itu kendala yang dialami oleh SMK Yayasan Bakti Prabumulih ini ialah penyampaian informasi 
tentang sekolah masih manual yaitu masih menggunakan brosur, spanduk dan juga harus datang langsung ke sekolah. Dengan penyampaian informasi yang demikian masih memiliki kekurangan, antara lain penyampaian informasi yang terbatas, kurang efektif dan efisien. Maka untuk membantu mempermudah dalam penyampaian informasi dan meningkatkan kualitas sekolah, Penulis akan membuat Website sekolah di SMK Yayasan Bakti Prabumulih agar masyarakat mudah dalam mencari informasi tentang sekolah ini.

Dalam pembuatan Website ini Penulis juga menerapkan metode $M V C$ sebagai pilihan dalam pengembangan sistemnya. Model View Controller $(M V C)$ adalah sebuah konsep yang diperkenalkan oleh penemu Smalltalk (Trygve Reenskaug) untuk membuat satu jenis data jaringan menjadi jenis data lainnya bersama dengan pemrosesan (model), mengisolasi dari proses manipulasi (controller) dan tampilan (view) untuk direpresentasikan pada sebuah user interface (Deacon, 2009).

\section{METODOLOGI PENELITIAN}

Penelitian ini menggunakan metode deskriptif kualitatif bertujuan untuk mendeskripsikan apa-apa yang saat ini berlaku. Di dalamnya terdapat upaya mendeskripsikan, mencatat, analisis dan menginterpretasikan kondisi yang sekarang ini terjadi atau ada. Dengan kata lain penelitian deskriptif kualitatif ini bertujuan untuk memperoleh informasiinformasi mengenai keadaan yang ada (Sitokdana dan Tanaamah, 2016:135). Sedangkan pada penelitian ini penulis menggunakan metode deskriptif kualitatif. metode deskriptif merupakan suatu metode dalam meneliti status kelompok manusia, suatu objek, suatu set kondisi, suatu sistem pemikiran ataupun suatu kelas peristiwa pada masa sekarang (Nazir, 2011:54).

Dalam hal terkait penelitian ini, sebagai prosedur pemecahan masalah yang diselidiki adalah dengan menggambarkan keadaan subjek atau objek yang berupa orang, lembaga, masyarakat dan yang lainnya berdasarkan fakta, karena pencarian informasi berdasarkan data yang akurat dalam merancang sistem yang diperlukan.

\subsection{Sumber Data}

\subsubsection{Data Primer}

Data primer merupakan sumber-sumber dasar yang merupakan bukti atau saksi utama dari kejadian yang lalu" (Nazir, 2011:50). Dalam hal ini peneliti mendapatkan secara langsung dari pihak SMK Yayasan Bakti Prabumulih.

\subsubsection{Data Sekunder}

Data sekunder adalah catatan tentang adanya suatu peristiwa ataupun catatan-catatan yang jaraknya telah jauh dari sumber orisinil” (Nazir, 2011:50).. Data Sekunder merupakan data pendukung informasi primer yang diperoleh berupa dokumen-dokumen tentang sekolah, buku bacaan, internet maupun observasi.

\subsection{Teknik Pengumpulan Data}

Dalam pengumpulan data untuk proses penelitian digunakan beberapa cara yaitu :

a. Observasi

Pengumpulan data dengan melakukan pengamatan secara langsung terhadap objek dan menganalisa masalah yang ada disana.

b. Wawancara

Pengumpulan data dengan cara melakukan komunikasi dan wawancara secara langsung dengan Pihak SMK Yayasan Bakti Prabumulih.

c. Studi Pustaka

Pengumpulan data dengan menggunakan atau mengumpulkan sumber tertulis, dengan cara membaca, mempelajari dan mencatat hal-hal penting yang berhubungan dengan masalah yang sedang dibahas.

d. Dokumentasi

Mengumpulkan dan mempelajari data dari sumber lain yang berhubungan dengan pengamatan langsung yang berupa foto atau video.

\subsection{Metode Pengembangan Sistem}

Model-View-Controller (MVC) adalah sebuah konsep yang diperkenalkan oleh penemu Smalltalk (Trygve Reenskaug) untuk membuat satu jenis paket data jaringan menjadi jenis data lainya bersama dengan pemrosesan (model), dari proses manipulasi (controller) dan tampilan (view) untuk dipresentasikan pada sebuah user interface (Deacon, 2009).

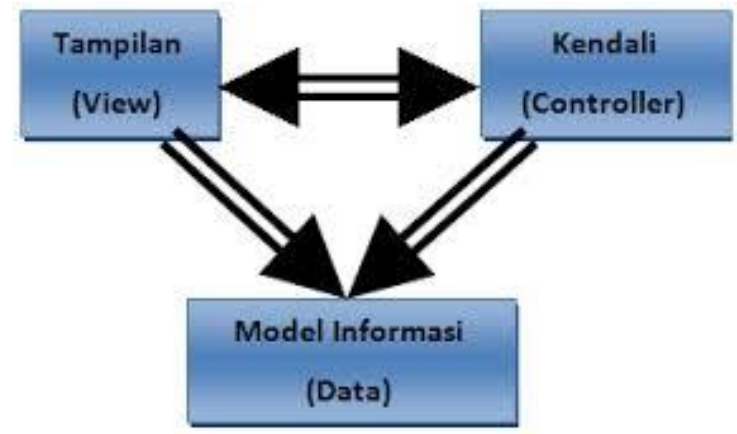

Sumber : J Deacon (2009)

Gambar 1. Metode MVC

Keterangan menurut gambar diatas alur dari Model View Controller sebagai berikut : 
a. Model

Model adalah bagian kode program yang menangani database, isi dari model merupakan bagian (fungsi-fungsi) yang berhubungan langsung dengan database untuk mengelola data seperti memasukkan data, pembaruan data, hapus data, dan lain-lain, namun tidak dapat berhubungan langsung dengan bagian view.

b. View

Tampilan (View). Bagian ini mengandung keseluruhan detail dari implementasi user interface. View adalah bagian kode program yang mengatur tampilan website. View biasanya berupa file skrip HTML. View juga berfungsi menampilkan data serta inputan user, jadi view merupakan halaman web.

\section{c. Controller}

Cara pemrosesan (Controller). Controller merupakan bagian yang menghubungkan model dan view. Controller berisi perintah-perintah yang bertanggung jawab untuk memproses suatu data dan mengirimkannya ke halaman web. Controller berfungsi untuk menerima request dan data dari user kemudian menentukan apa yang akan diproses oleh aplikasi.

\subsection{Alat Bantu Perancangan}

Alat bantu analisa dan perancangan yang dipakai adalah sebuah bahasa yang telah menjadi standar dalam industri untuk visualisasi, merancang, dan mendokumentasikan sistem perangkat lunak. Penulis menggunakan alat bantu analisa yaitu UML (Unified Modelling Languange). UML (Unified Modeling Language) adalah salah satu standar bahasa yang banyak digunakan di dunia industri untuk mendefinisikan requirement, membuat analisis \& desain, serta menggambarkan arsitektur dalam pemrograman berorientasi objek (Rosa A.S dan M. Shalahudin, 2015:133).

UML (Unified Modelling Languange) terdiri dari beberapa diagram diantaranya : Diagram Use Case Proses, Diagram Activity, Diagram Class.

\subsubsection{Use Case Diagram}

Use Case Diagram merupakan pemodelan untuk kelakukan (behavior) sistem informasi yang akan dibuat. Terdapat dua hal utama pada use case yaitu pendefinisian apa yang disebut Aktor dan use case
(Rosa dan Shalahudin, 2015:155).

\subsubsection{Class Diagram}

Class Diagram menggambarkan struktur sistem dari segi pendefinisian kelas-kelas yang akan dibuat untuk membangun sebuah sistem. Kelas memiliki atribut yaitu merupakan variabel-variabel yang memiliki oleh suatu kelas dan metode atau operasi adalah fungsi-fungsi yang dimiliki oleh suatu kelas (Rosa dan Shalahudin, 2015:141).

\subsubsection{Activity Diagram}

Diagram aktivitas atau activity diagram menggambarkan workflow (aliran kerja) atau aktivitas dari sebuah sistem atau proses bisnis atau menu yang ada pada perangkat lunak. Yang perlu diperhatikan disini adalah bahwa diagram aktivitas menggambarkan aktivitas sistem bukan apa yang dilakukan aktor, jadi aktivitas yang dapat dilakukan oleh sistem (Rosa dan Shalahudin, 2015:161).

\section{HASIL DAN PEMBAHASAN}

Dari hasil pengamatan dan penelitian yang dilakukan Penulis pada SMK Yayasan Bakti Prabumulih, penyampaian informasi masih menggunakan sistem manual. Dengan sistem yang berjalan sekarang ini siswa dan masyarakat masih kesuiltan untuk mendapatkan informasi tentang SMK Yayasan Bakti Prabumulih, serta waktu yang diperlukan untuk mendapatkan informasi sangat lama dan tidak akuratnya informasi yang didapatkan. Dalam sistem yang sedang berjalan pada SMK Yayasan Bakti Prabumulih, masih menggunakan brosur, spanduk dan masih harus datang langsung ke sekolah untuk menyampaikan informasi dan membutuhkan waktu yang lama, sehingga membuat sulitnya masyarakat dan siswa untuk mengetahui informasi yang ada saat ini pada SMK Yayasan Bakti Prabumulih.

Maka berdasarkan analisa tersebut diperlukan sebuah website yang kiranya dapat membantu menyampaikan informasi tentang SMK Yayasan BaktiPrabumulih dengan tidak menggunakan sistem manual dan brosur saja dan mempermudah untuk mendapatkan informasi tentang sekolah.

\section{Rancangan Sistem}




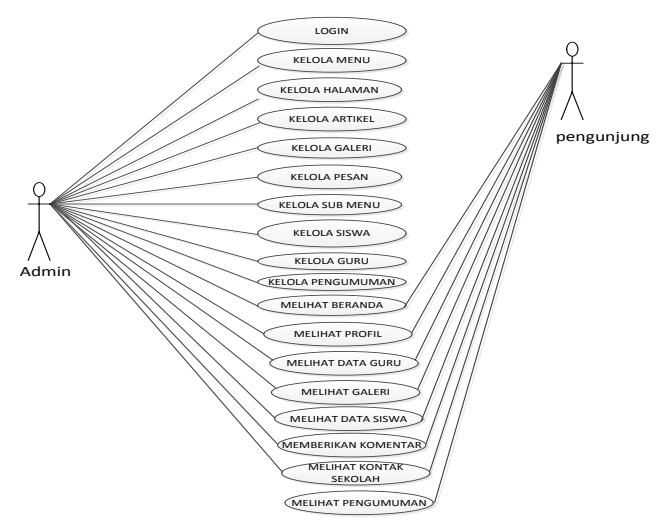

Gambar 2. Use Case Daigram

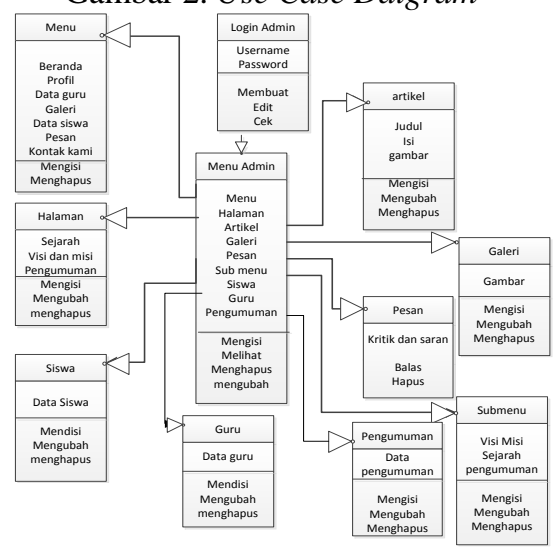

Gambar 3. Class Diagram

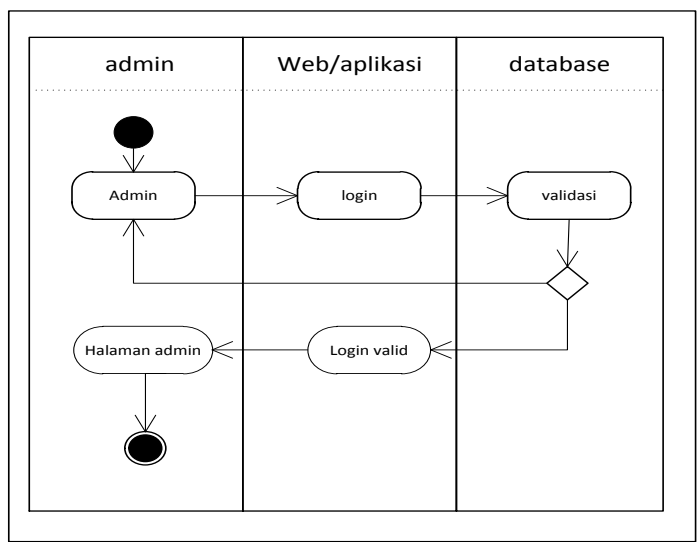

Gambar 4. Activity Diagram Login Admin

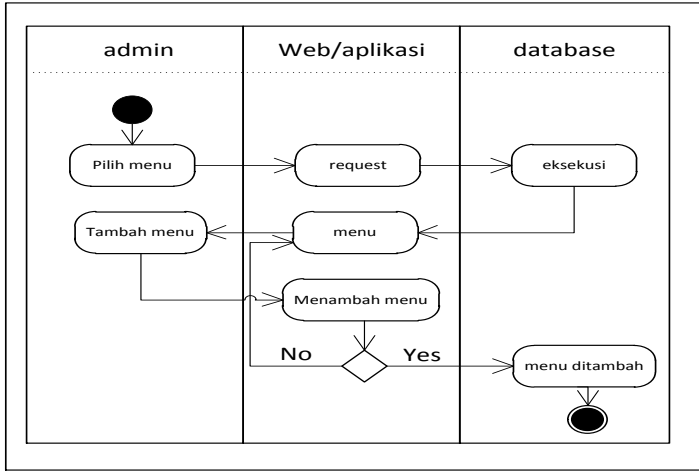

Gambar 5. Activity Diagram Admin input data menu

\section{Pembahasan}

Pada bagian pembahasan ini penulis menyajikan bahasan tentang apa yang akan kita temui pada website SMK Yayasan Bakti Prabumulih, menu dan langkah-langkah didalam pengoperasian dan serta proses menampilkan. Untuk menjalankan website SMK Yayasan Bakti Prabumulih dapat dilakukan sebagai berikut:

1. Nyalakan komputer tunggu komputer menampilkan area kerja.

2. Buka xampp klik start pada apache dan MySQl.

3. Buka web browser mozila firefox.

4. Dibagian addres

bar

ketikhttp://localhost/WEB/

5. Kemudian akan masuk kehalaman utama, masuk sebagai admin maka dibagian address bar ketik http://localhost/WEB/admin.

6. Kemudian akan masuk kehalaman login user, masukkan username dan password.

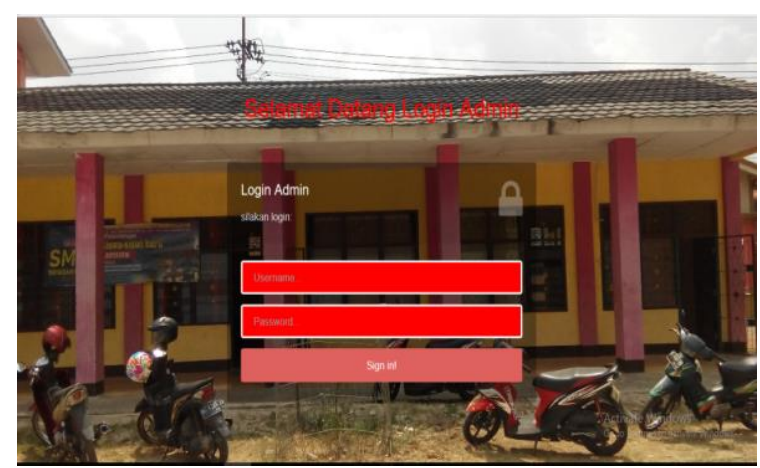

Gambar 6. Tampilan Form Login

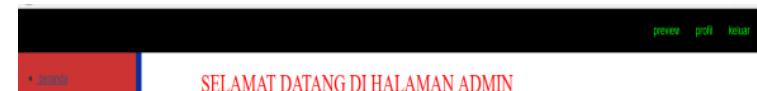

SMR YAYASA BAKTT PRABUMUIIH

SELAMAT DATANG DI HALAMAN ADM

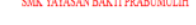

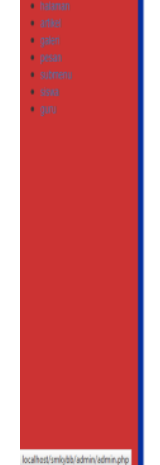

Gambar 7. Tampilan halaman admin 


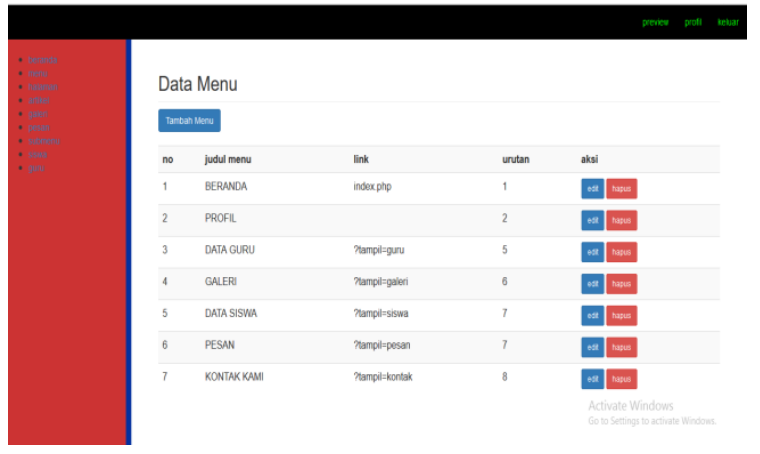

Gambar 8. Tampilan data menu

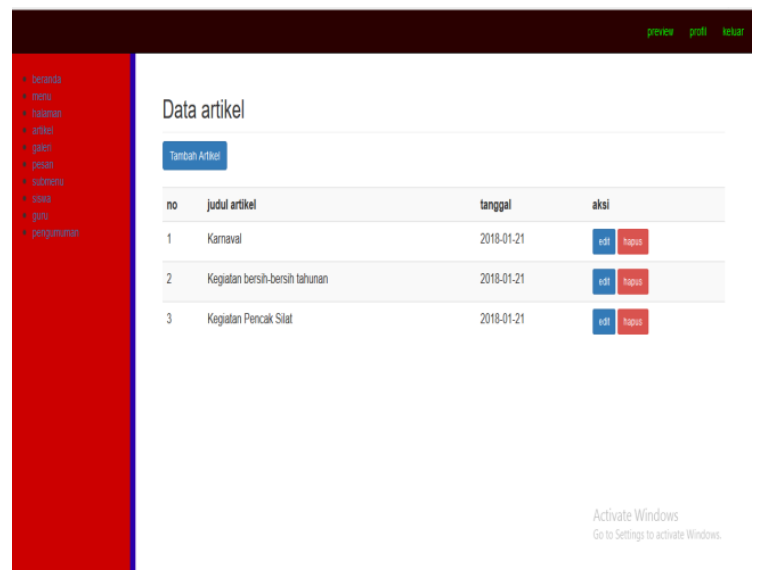

Gambar 9. Tampilan data artikel

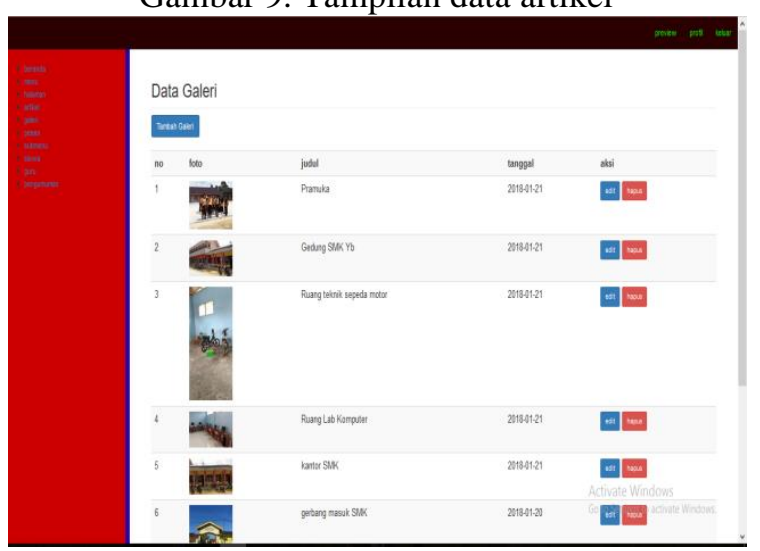

Gambar 10. Tampilan data galeri

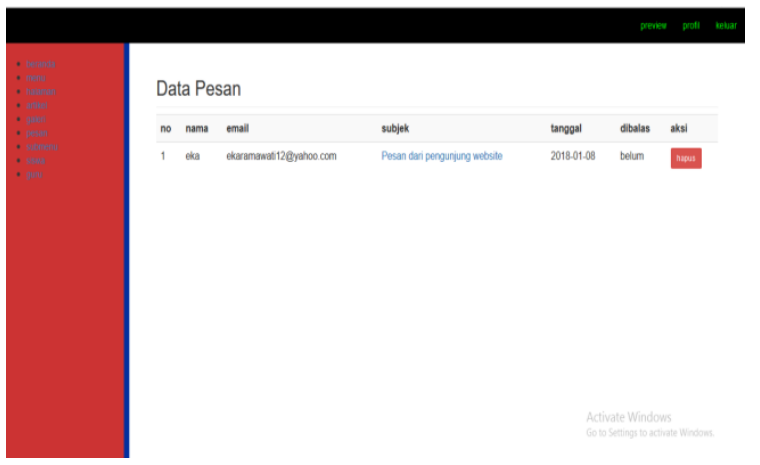

Gambar 11. Tampilan data pesan

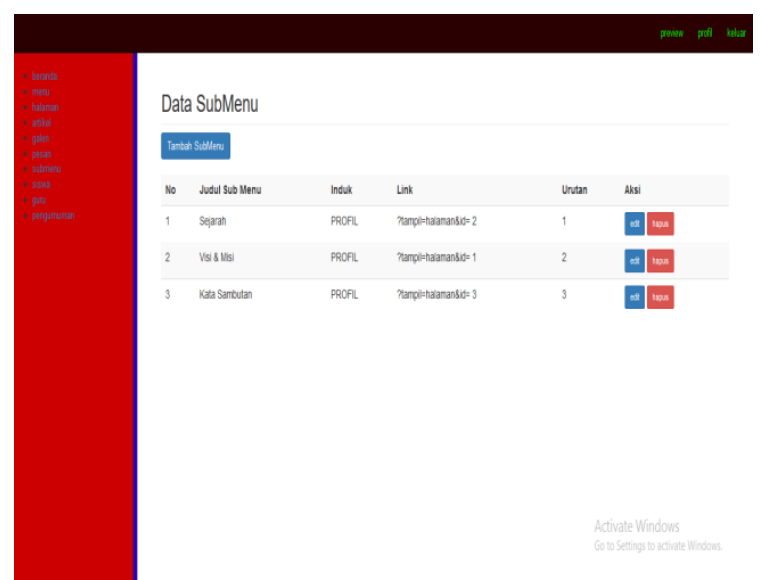

Gambar 12. Tampilan SubMenu

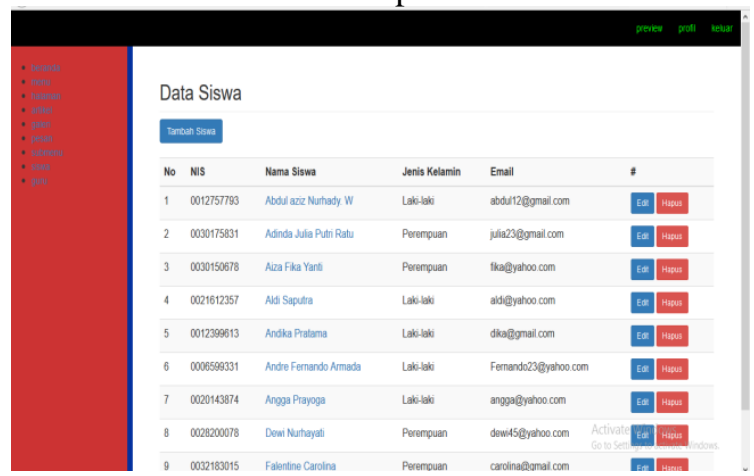

Gambar 13. Tampilan data siswa

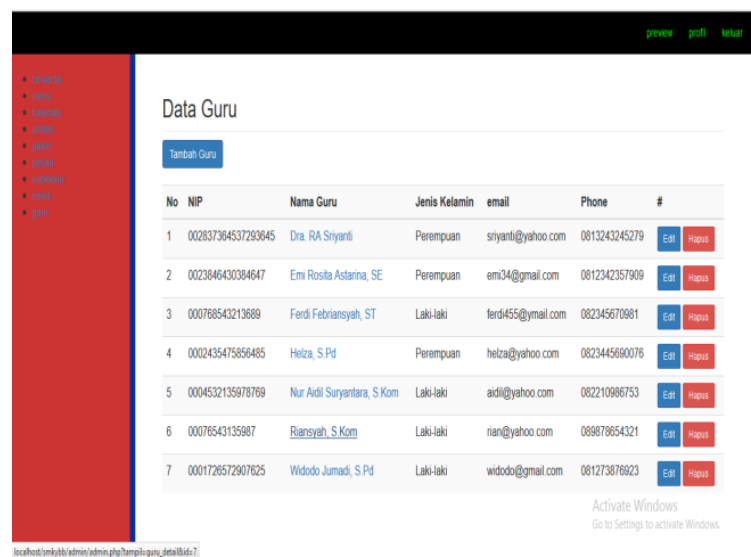

Gambar 14. Tampilan data guru

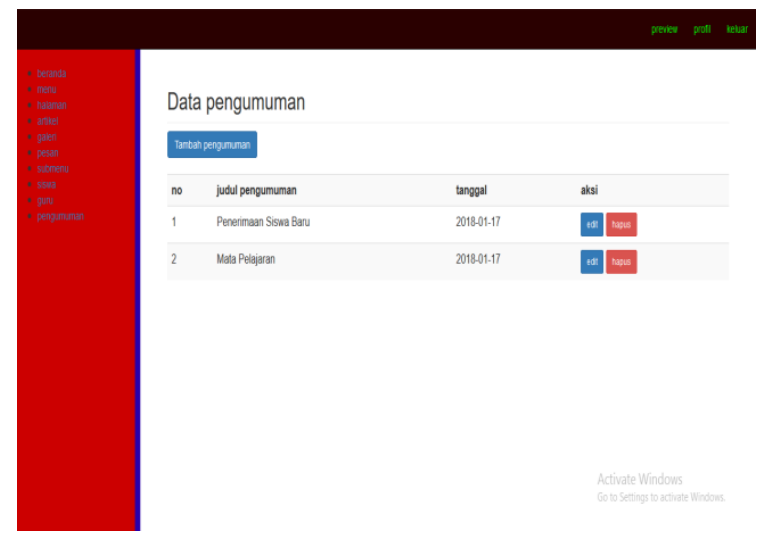


Gambar 15. Tampilan data pengumuman

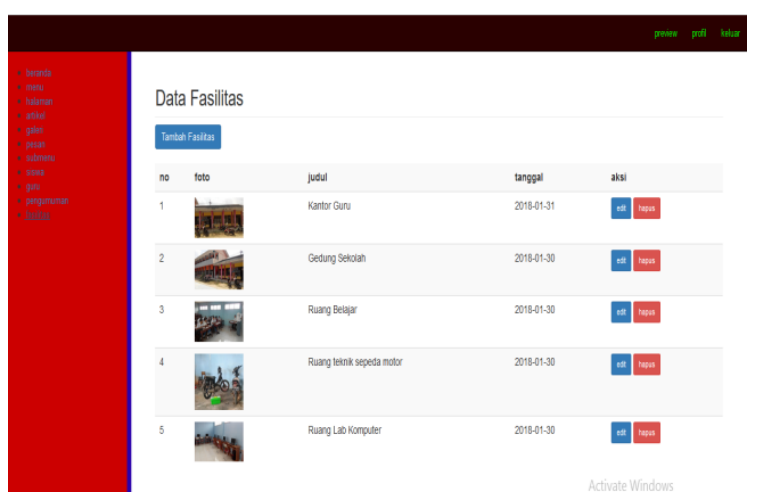

Gambar 16. Tampilan data fasilitas

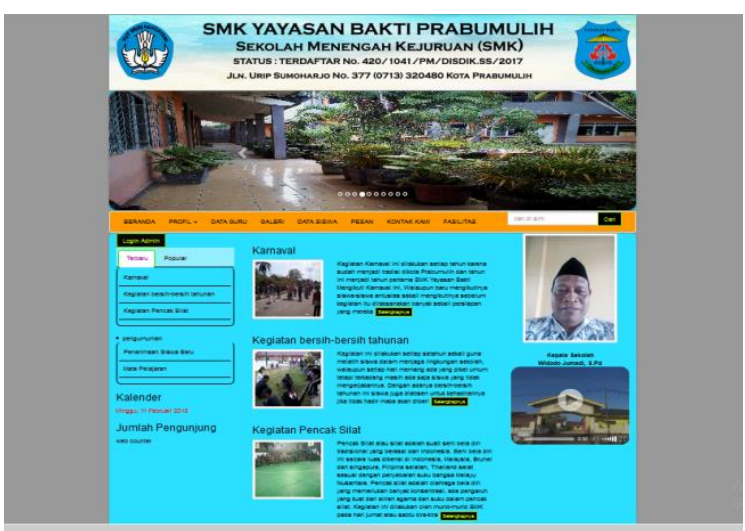

Gambar 17. Tampilan halaman utama

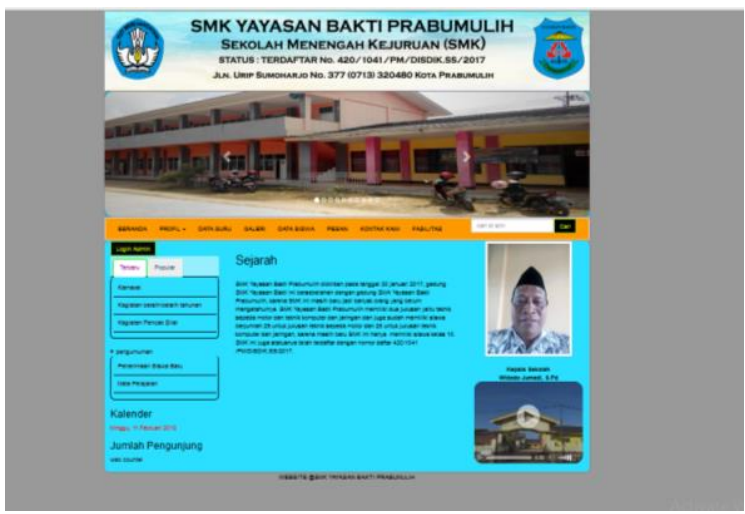

Gambar 18. Tampilan profil sekolah

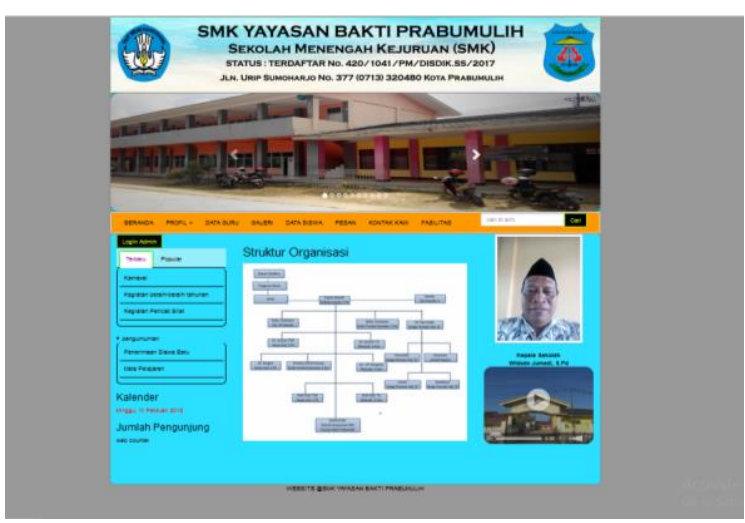

Gambar 19. Tampilan struktur organisasi

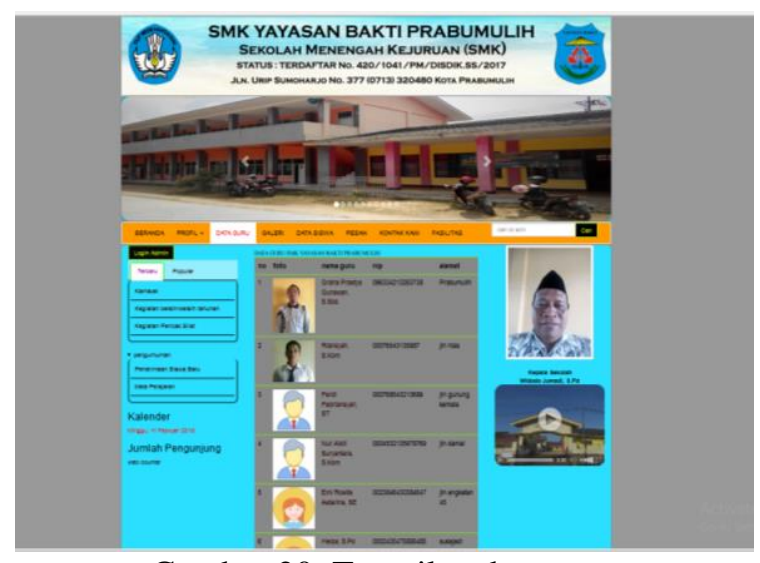

Gambar 20. Tampilan data guru

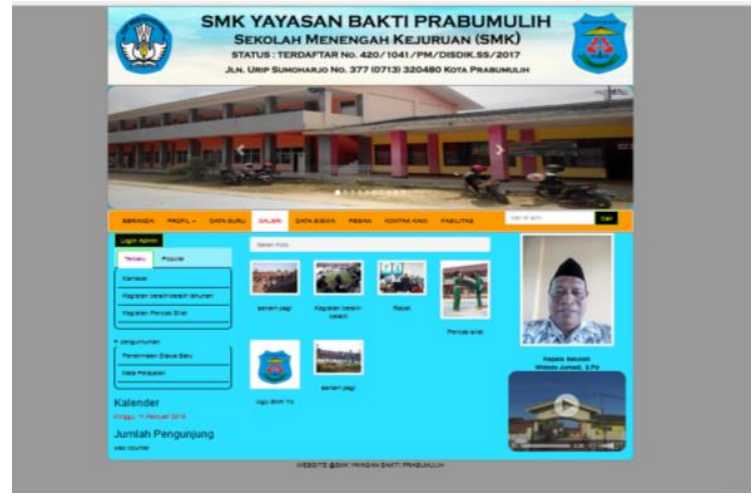

Gambar 21. Tampilan galeri

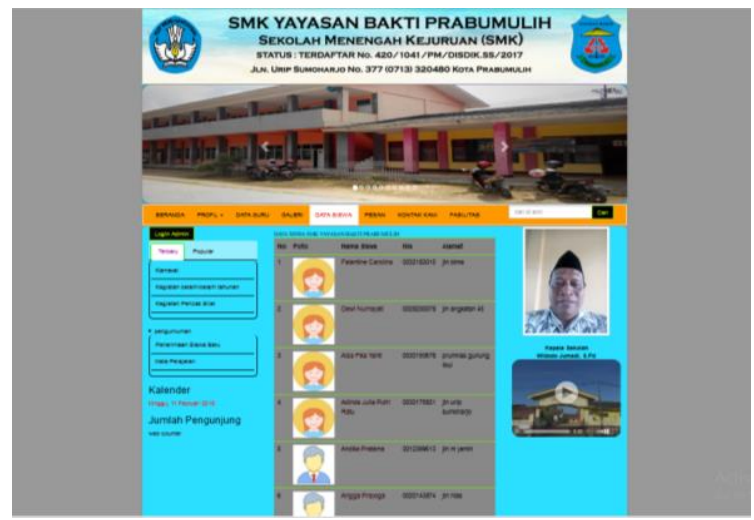

Gambar 22. Tampilan data siswa

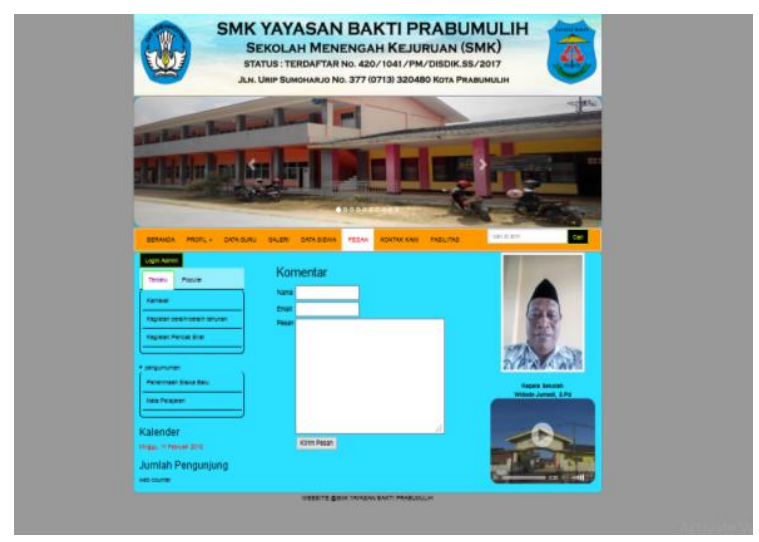

Gambar 23. Tampilan pesan 


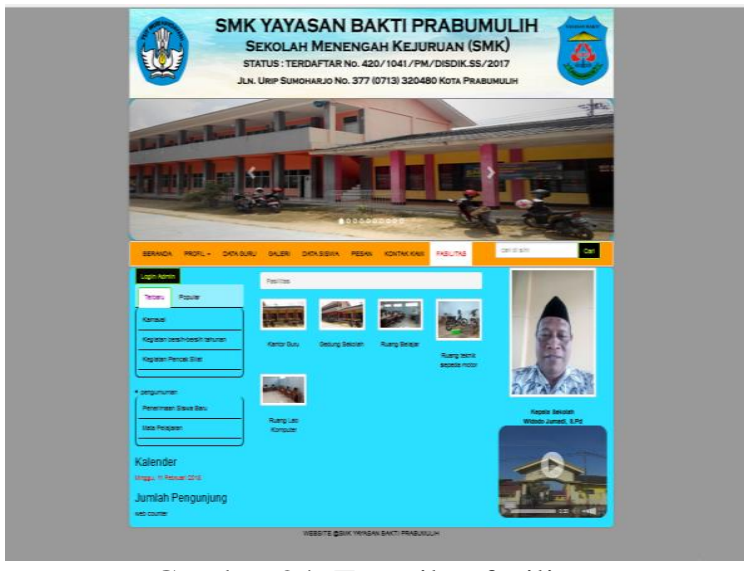

Gambar 24. Tampilan fasilitas

\section{KESIMPULAN}

Berdasarkan uraian penjelasan dan pembahasan keseluruhan pada penelitian ini, bahwa sistem yang saat ini sedang berjalan masih manual sehingga guru siswa dan masyarakat masih kesulitan dalam mendapatkan informasi tentang SMK Yayasan Bakti Prabumulih, maka disini penulis mengambil kesimpulan sebagai berikut :

1. Website dirancang dengan menggunakan bahasa pemrograman PHP dan database MySQL.

2. Dengan adanya website ini diharapkan dapat membantu Admin dalam pengontrolan dan pengolahan data informasi tentang sekolah.

3. Dapat memberikan kemudahan bagi masyarakat guru dan siswa dalam mencari informasi tentang SMK Yayasan Bakti Prabumulih.

\section{REFERENSI}

Abdulloh, Rohi. 2015. Web Programming is Easy. Jakarta : PT Elek Media Komputindo.

Ahmad. 2011. Sistem Informasi Manajemen Perusahaan. Jakarta : PT Elek Media

Komputindo.

EMS, Tim. 2014. Teori Dan Praktik PHP-MySQL Untuk Pemula. Jakarta : PT Elek Media Komputindo.

Enterprise Jubille. 2016. Belajar Sendiri Desain Web Dengan Dreamweaver. Jakarta : PT Elek media komputindo.

Fathurrahman. 2014. Membuat Website Mudah Dan Praktis Dengan Weebly. Jakarta : PT Elex Media Komputindo.

Kadir, Abdul. 2013. Buku Pintar Programmer Pemula PHP. Yogyakarta : MediaKom.

Kadir, Abdul. 2013. Pemrograman Database
MySQL untuk pemula. Yogyakarta :

MediaKom.

Kadir, Abdul \& Terra Ch. Triwahyuni. 2013. Pengantar Teknologi Informasi Edisi Revisi. Yogyakarta : ANDI.

Nasir, Moh. 2011. Metode Penelitian. Bogor : Ghalia Indonesia.

Pressman. 2010. Rekayasa Perangkat Lunak (Konsep Tehnik Penyusunan Laporan Keuangan). Jakarta : Penerbit Erlangga.

Raharjo, Budi. 2011. Belajar Otodidak Membuat Database Menggunakan MySQL. Bandung : informatika.

Raharjo, Budi. 2011. Belajar Otodidak Pemrograman Web Dengan PHP + Oracle. Bandung : informatika.

Rosa, Shalahuddin. 2014. Rekayasa Perangkat Lunak Terstruktur Dan Berorientasi Objek. Bandung : Informatika.

Rosa, Shalahuddin. 2015. Rekayasa Perangkat Lunak Terstruktur Dan Berorientasi Objek. Bandung : Informatika.

Sugiyono. 2011. Metode Penelitian Pendidikan Pendekatan Kuantitatif, Kualitatif dan $R \& D$. Bandung : CV. ALFABETA.

Winarno Edy, dkk. 2014. 24 Jam Belajar PHP. Jakarta : PT Elek Media Komputindo.

Winarno Edy, M.eng, Ali zaki. 2012. Mobile Web Development Dengan Dreamweaver. Jakarta : PT Elek Media Komputindo.

Bendriyanti Rita Prima, leni Natalia Zulita. 2012. Implementasi E-Arsip Pada Kanwil Kementerian Agama Provinsi Bengkulu. Bengkulu : jurnal Media Infotama Vol.8 No.1 Februari 2012. Issn : 1858-2680.

Bramwell A. Kasaedja, Rizal Sengkey, ST,. MT, Oktavian A. Lantang, ST., MT. 2014. Rancang Bangun Web Service Perpustakaan Universitas Sam Ratulangi. Manado : e-journal Teknik Elektro dan Komputer. Issn :2301-8402.

Fahrudin Bambang. 2016. Penerapan Algoritma Back Tracking Pada Permainan Capsa Banting. Medan : Jurnal Riset Komputer (Jurikom), Vol.3 No.6. Issn : 2407-389.

Hidayat Arief, Bayu surarso. 2012. Penerapan arsitektur Model View Controller (MVC) Dalam Rancang Bangun Sistem Kuis Online Adatif. Yogyakarta : Seminar Nasional Teknologi Informasi \& Komunikasi 2012 (Sentika 2012). Issn : 2089-9815.

I Gede Yudita Eka Prasetya. 2011. Desain Dan Implementasi Sistem Informasi Perpustakaan Berbasis Web Dengan MVC (Model View 
Controller). Bali : Jurnal Teknologi Dan Informatika (TEKNOMATIKA) Vol. 1 No.2.

Munir Sirojul, dkk. 2016. Perancangan Sistem Informasi Akademik Berbasis Web Menggunakan Framework MVC Pada Sekolah Tinggi Teknologi Terpadu Nurul Fikri. Dalam Jurnal Informatika terpadu Vol 2 No 1 Juli, 2016. Issn : 2460-8998.

Septima Anggiani, Eko Retnandi, Asep Deddy. 2012. Perancangan Sistem Informasi Berbasis website Subsistem Guru Di Sekolah Pesantren Persatuan Islam 99 Rancangbango. Garut. Issn : 2302-7339.

Syafitri Yulia Jihan. 2017. Perancangan Sistem Informasi Pemesanan Obat Menggunakan Bahasa Pemrograman Berorientasi Objek. Padang : UPI YPTK Jurnal KomTekinfo Vol.4 No.1, Juni 2017. Issn : 2356-0010.

Syamnugroho Imam Teguh, Rissal Efendi. 2014. Pengembangan website SMK Negeri 4 Semarang. Semarang : Jurnal Teknologi Informasi dan Komunikasi Vol.5 No.2. Issn : $2087-0868$

Sitokdana, Melkior dan Tanaamah Andeka Rocky. 2016. Strategi Pembangunan E-Culture di Indonesia. dalam Jurnal Teknik Informatika dan Sistem Informasi Vol 2 No 2 Agustus 2016, hlmn.139.

Wibowo Kadek. 2015. Penerapan Sistem Informasi Akademik Berbasis Web (Studi Kasus MTs. Maulana Ishaq Banyuwangi). Jakarta : Seminar Nasional Inovasi dan Tren (SNIT) 2015, hlmn.A.119.

\section{PROFIL PENULIS}

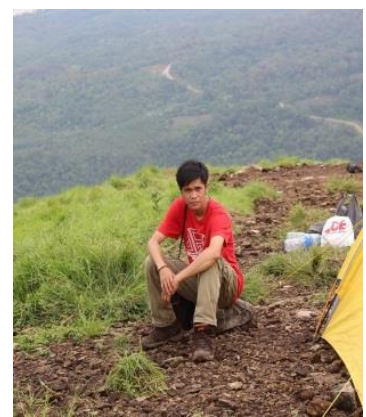

Khana Wijaya lahir di Payaraman 14 Agustus 1990. Lulusan S1 dan S2 Universitas Binadarma Palembang. Bergabung dengan STMIK Prabumulih mulai tahun 2014 sampai saat ini sebagai dosen Program Studi Sistem Informasi.

Jurnal yang pernah saya buat berjudul Analisis Tingkat Kepuasan Pelanggan Terhadap Website Winro Pada PT. Indo Tirta Sriwijaya Prabumulih.

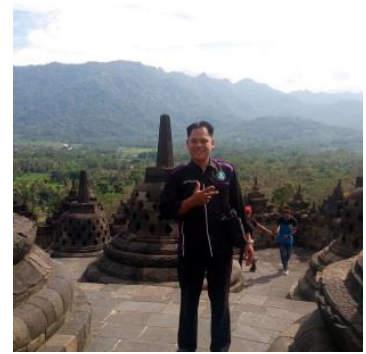

Andi Christian Dosen STMIK Prabumulih sejak tahun 2008. Saat ini sedang menajabt sebagai ketua progrma studi sistem informasi (S1). Jurnal yang pernah saya buat adalah Rancang Bangun Website Program Studi

Smk Negeri 2 Prabumulih Menggunakan Framework Bootstrap. 